\title{
HABITUAL PHYSICAL ACTIVITY IN ADULTS MEASURED BY ACCELEROMETER IN COMPLIAMCE WITH SELECTED HEALTH RECOMMENDATIONS
}

\author{
Małgorzata Dębska, 1, A, B, C, D Władysław Mynarski, ${ }^{1, A, ~ B, ~ D ~ M i c h a ł ~ R o z p a r a, ~} 1$, B, C \\ Daniel Puciato ${ }^{2, D}$ \\ ${ }^{1}$ Faculty of Physical Activity, Department of Tourism and Health-Oriented Physical Activity, The Jerzy Kukuczka Academy of Physical \\ Education, Katowice, Poland \\ ${ }^{2}$ Faculty of Physical Activity and Physiotherapy, Institute of Tourism and Leisure, University of Technology, Opole, Poland

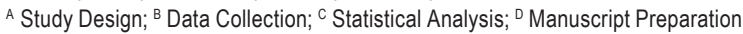

\author{
Address for corpespondence: \\ Małgorzata Dębska, PhD \\ The Jerzy Kukuczka Academy of Physical Education, \\ Department of Tourism and Health-Oriented Physical Activity \\ Mikołowska 72A, 40-065 Katowice, Poland \\ E-mail: mal.debska@interia.pl
}

\begin{abstract}
Ahstract The aim of the present study was the evaluation of habitual physical activity in adult members of health promoting associations in compliance with selected health recommendations. Physical activity was monitored for 7 consecutive days using accelerometer ActiGraph GT3X+. It was observed that the percentages of individuals with sufficient physical activity differ depending on healthoriented recommendation used in the evaluation. The results indicated that despite appropriate weekly volume of physical activity expressed in energy expenditure (on the average, twice as high as the recommended minimum) and the number of steps taken daily, the prevailing majority of participants $(60 \%)$ demonstrated an inadequate level of it when assessed in the context of recommendation by World Health Organization.
\end{abstract}

Key words accelerometry, health recommendations, physical activity associations, adults

\section{Introduction}

Reasonable physical activity (PA) has positive impact on the functioning of human body, with the positive changes in individual systems and organs occurring, due to both aerobic or anaerobic physical efforts. Regular aerobic physical activity causes positive adaptive changes in the cardiorespiratory system and in metabolic processes. By contrast, regular anaerobic exercise primarily stimulates adaptive functions of the locomotor system and increases muscular strength and enhances the osteoarticular system (Li, Siegrist, 2012; Molmen-Hansen, Stolen, Tjonna, Aamot, Ekeberg, Tyldum, 2012; Westcott, 2012, Van Roie, Delecluse, Coudyzer, Boonen, Bautmans, 2013) 
Physical activity has a comprehensive positive impact on human body only when it meets certain quantitative and qualitative characteristics. Major quantitative PA characteristics is its volume indexed by the duration, energy expenditure, and distance covered, among other things. An important qualitative PA characteristic is its intensity, looking at: the pace of activity, the number of the Metabolic Equivalents of Task (MET), post-exertion heart rate $(H R)$, level of fatigue and other factors.

Characteristics necessary for one's health to improve are referred to in the global body of research as health recommendations. Any health recommendation may be defined on the basis of a single PA characteristic such as the number of steps $-7,500$ steps a day, energy expenditure connected to PA - 2,000 kcal/week or two or more characteristics, e.g. the duration and intensity of an activity $-5 \times 30$ minutes $\times 4-6$ METs (Tudor-Locke, Hatano, Pangrazi, Kang, 2008; Tudor-Locke et al., 2011; Rahl, 2010). The most frequently discussed recommendations for PA characteristics as regards health benefits have been thoroughly reviewed in Rahl's research (2010).

The varying general or specific nature of particular recommendations and differences between PA characteristics that these recommendations are based on inevitably raise the question of the agreement between assessments of individual's PA models against different recommendations. It is not by coincidence that results of individual's habitual PA in compliance with diverse health recommendations examinations have recently been presented in specialist literature (El Ansari, Khalil, Crone, Stock, 2014; Martinez-Gomez et al., 2010). No research projects such as those have been carried out in Poland yet.

The aim of the present study was the evaluation of habitual physical activity in adult members of health promoting associations in compliance with selected health recommendations. We wanted to answer the following questions in this manuscript:

1. Does the majority of members of examined associations meet the physical activity health recommendations?

2. Do various criteria of physical activity evaluation (weekly energy expenditure on PA, number of steps taken, duration of moderate-to-vigorous PA) differentiate the percentages of subjects meeting them?

\section{Materials and methods}

The study was approved by Jerzy Kukuczka Academy of Physical Education Research and Ethics Committee (2/2012). All subjects have provided written consent for the use of information collected during examination.

This study involved 50 participants: 16 women and 34 men - members of health promoting associations in Dabrowski Basin (Poland). The selection of the study group was intentional - we assumed that members of above-mentioned associations were more physically active than general population. The majority of participants had a normal physique (BM $57.9 \pm 7.5[\mathrm{~kg}]$ in women and $74.2 \pm 8.9[\mathrm{~kg}]$ in men, $\mathrm{BF} 21.9 \pm 6.6[\%]$ in women and 14.5 \pm 6.0 [\%] in men, BMI $21.9 \pm 2.5$ in women and $23.6 \pm 2.8$ in men, WHR $0.79 \pm 0.05$ in women and $0.89 \pm 0.06$ in men).

Data was collected with the use of indirect observation as a method and accelerometry as the technology. PA characteristics were assessed for 7 consecutive days using accelerometer ActiGraph GT3X+ in April and May 2014. The prevailing form of activity undertaken by members of examined associations was jogging.

The below characteristics of basic weekly physical activity were measured:

- the number of steps taken for 7 consecutive days of the monitoring,

- weekly energy expenditure on PA [kcal/week],

- weekly duration of total moderate physical activity (MPA [min]),

- weekly duration of moderate physical activity accumulated in 10 minute bouts (MPA in 10 min. bouts [min]), 
- weekly duration of total vigorous physical activity (VPA [min])

- weekly duration of vigorous physical activity accumulated in 10 minute bouts (VPA in 10 min. bouts [min]).

The values of those variables were evaluated in the context of recommended weekly energy expenditure on PA (respecting global volume of PA) (Paffenbarger, Hyde, Wing, 1990) daily number of steps (respecting global volume and frequency of PA (Tudor-Locke, Hatano, Pangrazi, Kang, 2008, Tudor-Locke, Hatano, Pangrazi, Kang, 2011) and the duration of moderate-to-vigorous PA as recommended by World Health Organization (WHO, 2010). For that purpose, the data was compared with:

1. Recommended weekly energy expenditure on PA, which should be the minimum of 2,000 kcal in any 20-59 year-old with a body mass of $70 \mathrm{~kg}$ (Paffenbarger, Hyde, Wing 1990). Individual values of it were derived with the following formula:

\section{RWEE $=2,000[\mathrm{kcal} / \mathrm{week}] \times \mathrm{BM}[\mathrm{kg}] / 70 \mathrm{~kg}$,}

where: RWEE - recommended weekly energy expenditure [kcal/week] on PA in people aged 20-59, $\mathrm{BM}$ - body mass $(\mathrm{kg})$.

2. The five-step scale of physical activity by Tudor-Locke et al. (2011), who defined the following classification of the individual's PA volume based on the number of steps taken daily: 5,000 - individuals with sedentary lifestyles, 5,000-7,499 - individuals with low PA, 7,500-9,999 - individuals with moderately active lifestyles, 10,000-12,499 - individuals with high PA (the minimum for health benefits to occur), $\geq 12,500$ - individuals with very high $\mathrm{PA}$.

3. WHO's recommendation, providing that the individual should engage in at least 150 minutes of aerobic MPA per week or at least 75 minutes of aerobic VPA per week or an equivalent combination of moderate and vigorous intensity activity just to sustain or improve health (150 min MVPA). This physical activity should be accumulated in bouts of at least 10 minutes (WHO, 2010).

The principal descriptive statistics ( $\bar{x}, S D$, max, min) of analyzed variables and percentage rates $(\%)$ of participants satisfying and not satisfying PA health recommendations were calculated in Statistica 10 Statsoft Inc.

\section{Results}

Individually estimated recommended weekly energy expenditure on PA ranged from 1377 to 2797 [kcal]. The actual value of this parameter estimated from accelerometer was between 1443 to 8522 [kcal]. On the average, the participants expended 4,257.2 [kcal] on physical activity per week, more than twice as much as the minimum recommended for the individual to sustain or improve their health (Table 1). The mean weekly duration of MPA (735.2 \pm 337.1 [min]) was more than eight times longer than VPA ( $83.8 \pm 81.5$ [min]). Meeting the criterion of accumulating $\mathrm{PA}$ in at least $10 \mathrm{~min}$. bouts reduced MPA volume throughout the week five times (137.8 \pm 124.0 [min]). Vigorous physical efforts with such a minimum duration (VPA in $10 \mathrm{~min}$. bouts) occured in less than half of all participants (20) (Table 1).

All men and women (100\%) demonstrated proper weekly PA volume expressed in energy expenditure [kcal]. The prevailing majority of participants $(98 \%)$ took recommended number of steps $(10,000)$ each day, a criterion was not fulfilled by just $2 \%$ of all participants (1 woman) (Table 2). Less than half of all subjects (40\%) satisfied WHO's recommendation for the weekly volume of PA specified as total duration time and intensity (150 minutes of MVPA [min/week]). This guideline was met merely by $41.2 \%$ of men and $37.5 \%$ of women (Table 2 ). 
Table 1. The principal characteristics of participants' physical activity

\begin{tabular}{lccc}
\hline \multicolumn{1}{c}{ Variable } & $\mathrm{n}$ & $\overline{\mathrm{x}} \pm \mathrm{SD}$ & $\min -\max$ \\
\hline Weekly energy expenditure on & 50 & $4257.2 \pm 1628.8$ & $1443.0-8522.0$ \\
PA [kcal/week] & & & $1377.0-2797.0$ \\
RWEE on PA [kcal/week] & 50 & $1989.0 \pm 330.9$ & $6732.4-25404.3$ \\
Number of steps taken daily & 50 & $10653.0 \pm 4000$ & $311.0-1864.0$ \\
MPA [min/week] & 50 & $735.2 \pm 337.1$ & $10.0-388.0$ \\
MPA in 10 min. bouts [min/week] & 47 & $137.8 \pm 124.0$ & $2.0-349.0$ \\
VPA [min/week] & 48 & $83.8 \pm 81.5$ & $11.0-296.0$ \\
VPA in 10 min. bouts [min/week] & 20 & $101.6 \pm 85.5$ & \\
\hline
\end{tabular}

RWEE - recommended weekly energy expenditure, MPA - moderate physical activity, VPA - vigorous physical activity.

The reason why the majority of participants failed to satisfy recommendation by WHO was that they rarely took up activities accumulated in at least 10 minutes bouts - a precondition defined in this health-oriented guideline. An evident trend was observed that the degree to which all health-oriented PA recommendations considered in this study were fulfilled in men was slightly higher than in women (Table 2).

Tahle 2. Compliance with selected health recommendations for physical activity

\begin{tabular}{lccc}
\hline \multicolumn{1}{c}{ Recommendation } & Women & Men & General \\
\hline Recommended weekly energy expenditure on PA (Paffenbarger i in., 1990) & $(16) 100 \%$ & $(34) 100 \%$ & $(50) 100 \%$ \\
7.500 steps each day (Tudor-Locke et al., 2011) & $(15) 93.8 \%$ & $(34) 100 \%$ & $(49) 98 \%$ \\
150 min MPA or 75 min VPA or equivalent (WHO, 2010) & (6) $37.5 \%$ & (14) $41.2 \%$ & $(20) 40 \%$ \\
\hline
\end{tabular}

\section{Discussion}

The aim of this study was to investigate habitual physical activity in members of health promoting associations in compliance with basic health recommendations. The evaluation of physical activity in the context of getting health benefits in members of such associations has not been the aim of domestic studies yet.

The prevailing number of domestic studies related to PA assessment are conducted with the use of subjective methods (Bergier, Bergier, Soroka, Kubińska, 2010; Biernat, Piątkowska, 2012; Nawrocka, Prończuk, Mynarski, Garbaciak, 2012). These methods consist in estimating PA parameters from questionnaires and their results tend to be overestimated (Biernat, 2011, Pate et al., 2015). In our research, we used the three-axial accelerometer ActiGraph GT3X+ in order to raise the quality of results of PA monitoring. Objective tools of PA assessment, which validity and reliability are high (Lipert, Jegier, 2009; Rothney, Brychta, Meade, Chen, Buchowski, 2010; Butte, Ekelund, Westerterp, 2012; Thomas, Silverman, Nelson, 2015), are commonly used by foreign researchers (Colley et al., 2011, Ruiz et al., 2011, Evenson, Buchner, Morland, 2012; Sheers, Philippaerts, Lefevre, 2013; Mutikainen, Helander, Pietilä, Korhonen, Kujala, 2014). In Poland, research on PA characteristics based on impartial measurement tools is still scarce (Mynarski, Nawrocka, Rozpara, Garbaciak, 2012; Włodarek, Majkowski, Majkowska, 2012). 
The results of our research indicated that the weekly energy expenditure on habitual physical activity among examined members of health promoting associations was high, because it exceeded on average twice the recommended level (RWEE). Additionally during the week of monitoring, a vast majority of participants (98\%) took an adequate number of steps to fulfill the recommendation by Tudor-Locke et al. (2011). The results of authors' own research are pretty optimistic in the light of those demostrated in another researches (Chastin et al., 2009, Bassett, Wyatt, Thompson, Peters, Hill, 2010; Hirvensalo et al., 2011; Biernat, 2011; Colley et al., 2011; Pate et al., 2015). The possible reason of that is the fact that our study looked exclusively on members of health promoting associations, who seem to be more physically active than the general population.

Despite high weekly energy expenditure on PA and number of steps taken less than half of participants (40\%) met the criterion of recommended weekly duration of moderate-to-vigorous PA in the context of WHO guideline. It indicates that low intensity physical activity was dominant in the members of examined associations' typical week. The percentage rate of individuals meeting WHO criterion of PA was high in comparison with the results of Canadians conducted by Colley et al. (2011) (15,5\%) and similar to these indicated in Finnish employees by Multikainen et al. (42\%) (2014). It should be emphasized that citizens of above mentioned countries are recognized as one of the most physicaly active all over the world. More optimistic results (73\%) were indicated in Flemish by Scheers et al. (2013).

The main reason for the high percentage rate of men and women not satisfying health recommendations for PA as defined by WHO was that the activities undertaken by research participants were rarely accumulated in minimum 10 minutes bouts (WHO, 2010).

What points to that are authors' own observations, as only $40 \%$ of women and men participating in this study satisfied WHO PA recommendation (including duration and intensity 150 min MVPA), whilst regarding less complex criteria by Paffenbarger et al. (1990) (including only volume) or Tudor-Locke et al. (2011) (including volume and frequency) all of them or mostly all meet health-oriented recommendation. The consequences of various basic criteria of physical activity assessment, included in health-oriented recommendations, are quite significant differences in PA evalutaion even in the same study group (percentages of compliance with PA guidelines are unlike). A similar trend was observed in research conducted by Chastin et al. (2009), Scheers et al. (2013) and Chaix et al. (2014) where the degree to which a PA recommendation was satisfied differed depending on the criterion used in the evaluation. There are still only few publications investigating this problem.

In relation to the results of this manuscript and the fact of existing diversified criteria of health-oriented PA assessment, it seems to be important to evaluate habitual PA of certain social group in compliance with different recommendations simultaneously in order to receive an overview of the proportion of people being sufficiently active.

\section{Conclusions}

The aim of this study was to investigate habitual physical activity in adult members of health promoting associations in compliance with selected PA characteristics recommended for health benefits to occur. The below conclusions summarize the results of this study:

1. Despite appropriate weekly volume of PA expressed as energy expenditure (on the average, twice as high as the recommended minimum) and the number of steps, the prevailing majority of participants demonstrated an inadequate level of PA when assessed according to WHO's recommendation. 
2. It was observed that the percentage rate of individuals with appropriate physical activity differs depending on the criterion used in the evaluation.

\section{References}

Bassett, Jr, D.R., Wyatt, H.R., Thompson, H., Peters, J.C., Hill, J.O. (2010). Pedometer-measured physical activity and health behaviors in United States adults. Med Sci Sports Exerc, 42 (10), 1819.

Bergier, J., Bergier, B., Soroka, A., Kubińska, Z. (2010). Aktywność fizyczna pielęgniarek z uwzględnieniem ich wieku. Medycyna Ogólna, 16, 595-605.

Biernat, E. (2011). Physical activity of Warsaw's population based on selected occupational groups. Warszawa: SGH.

Biernat, E., Piątkowska, M. (2012). Rekreacyjna aktywność fizyczna Polaków na tle Europy. Raport dla Departamentu Analiz i Polityki Sportowej Ministerstwa Sportu i Turystyki. Warszawa: Ministerstwo Sportu i Turystyki.

Butte, N.F., Ekelund, U., Westerterp, K.R. (2012). Assessing physical activity using wearable monitors: measures of physical activity. Med Sci Sports Exerc, 44 (1), 512.

Catenacci, V.A., Ogden, L.G., Stuht, J., Phelan, S., Wing, R.R., Hill, J.O., Wyatt, H.R. (2008). Physical activity patterns in the national weight control registry. Obesity, 16 (1), 153-161.

Chaix, B., Kestens, Y., Duncan, S., Merrien, C., Thierry, B., Pannier, B. (2014). Active transportation and public transportation use to achieve physical activity recommendations? A combined GPS, accelerometer, and mobility survey study. IJBNPA, 11. DOI:10.1186/s12966-014-0124-x.

Chastin, S.F.M., Dall, P.M., Tigbe, W.W., Grant, M.P., Ryan, C.G., Rafferty, D., Granat M.H. (2009). Compliance with physical activity guidelines in a group of UK-based postal workers using an objective monitoring technique. Eur J Appl Physiol, 106, 893-899.

Colley, R., Garriguet, D., Janssen, I., Craig, C.L., Clarke, J., Tremblay, M.S. (2011). Physical activity of Canadian adults: accelerometer results from the 2007 to 2009 Canadian Health Measures Survey. Public Health Reports, 22 (1), 7-14.

El Ansari, W., Khalil, K., Crone, D., Stock, C. (2014). Physical activity and gender differences: correlates of compliance with recommended levels of five forms of physical activity among students at nine universities in Libya. Cent Eur J Public Health, 22 (2), 98-105.

Evenson, K.R., Buchner, D.M., Morland, K.B. (2012). Objective measurement of physical activity and sedentary behavior among US adults aged 60 years or older. Prev Chronic Dis, 9.

Hirvensalo, M., Telama, R., Schmidt, M.D., Tammelin, T.H., Yang, X., Magnussen, C.G., Raitakari, O.T. (2011). Daily steps among Finnish adults: Variation by age, sex, and socioeconomic position. Scand J Public Health, 39 (7), 669-677.

Li, J., Siegrist, J. (2012). Physical Activity and Risk of Cardiovascular Disease - A Metaanalysis of Prospective Cohort Studies. Int J Environ Res Public Health, 9 (2), 391-407.

Lipert, A, Jegier, A. (2009). Metody pomiaru aktywności ruchowej człowieka. Polish J Sport Med, 25 (6), 155-168.

Martinez-Gomez, D., Ruiz, J.R., Ortega, F.B., Veiga, O.L., Moliner-Urdiales, D., Mauro, B. (2010). Recommended levels of physical activity to avoid an excess of body fat in European adolescents: the HELENA Study. Am J Prev Med, 39 (3), 203-211.

Molmen-Hansen, H.E., Stolen, T., Tjonna, A.E., Aamot, I.L., Ekeberg, I.S., Tyldum G.A. (2012). Aerobic interval training reduces blood pressure and improves myocardial function in hypertensive patients. Eur J Prev Cardiol, 19, 151-160.

Mutikainen, S., Helander, E., Pietilä, J., Korhonen, I., Kujala, U.M. (2014). Objectively measured physical activity in Finnish employees: a cross-sectional studies. BMJ Open Journal, 4. DOI:10.1136/bmjopen-2014-005927.

Mynarski, W., Nawrocka, A., Rozpara, M., Garbaciak, W. (2012). Physical activity of male and female adolescents living in a town and a city in the context of public health recommendations. Biomed Hum Kinetics, 4, 18-23.

Nawrocka, A., Prończuk, A., Mynarski, W., Garbaciak, W. (2012). Physical activity of top level managers in the context of the public health recommendations. Med $\operatorname{Pr}, 63$ (3), 271-279.

Paffenbarger, J.R.S., Hyde, R.T., Wing, A.L. (1990). Physical activity and physical fitness as determinants of health and longevity. In: C. Bouchard, R.J. Shephard, T.S. Stephens, J.R. Sutton, B.D. McPherson (eds.), Exercise, fitness, and health (pp. 33-48). Champaign: Human Kinetics Publishers.

Pate, R.R., Mclver, K.L., Colabianchi, N., Troiano, R.P., Reis, J.P., Carroll, D.D. (2015). Physical activity measures in the Healthy Communities Study. Am J Prev Med, 49 (4), 653-659.

Rahl, R.L. (2010). Physical Activity and Health Guidelines: Recommendations for Various Ages, Fitness Levels, and Conditions from 57 Authoritative Sources. Champaign: Human Kinetics Publishers. 
Rothney, M.P., Brychta, R.J., Meade, N.N., Chen, K.Y., Buchowski, M.S. (2010). Validation of the ActiGraph two-regression model for predicting energy expenditure. Med Sci Sports Exerc, 42, 1785-1792.

Ruiz, J.R., Ortega, F.B., Martínez-Gómez, D., Labayen, I., Moreno, L.A., De Bourdeaudhuij, I. (2011). Objectively measured physical activity and sedentary time in European adolescents the HELENA study. Am J Epidemiol, 11. DOI: 10.1093/aje/kwr068.

Sheers, T., Philippaerts, R., Lefevre, J. (2013). Compliance with different physical activity recommendations and its association with socio-demographic characteristics using an objective measure. BMC Public Health, 13, 136-145.

Thomas, J.R., Silverman, S., Nelson, J. (2015). Research Methods in Physical Activity. Champaign: Human Kinetics.

Tudor-Locke, C., Hatano, Y., Pangrazi, R.P., Kang, M. (2008). Revisiting: How many steps are enough? Med Sci Sports Exerc, 40, 537-543.

Tudor-Locke, C., Craig, C.L., Brown, W.J., Clemes, S.A., De Cocker, K., Bourdeaudhuij, I.D. (2011). How Many Steps/day are Enough? For Adults. Int J Behav Nutr Phys Act, 8, 79-98.

Van Roie, E., Delecluse, C., Coudyzer, W., Boonen, S., Bautmans, I. (2013). Strength training at high versus low external resistance in older adults: Effects on muscle volume, muscle strength, and force-velocity characteristics. Exp Gerontol, 48 (11), $1351-1361$.

Westcott, W.L. (2012). Resistance Training is Medicine: Effects of Strength Training on Health. Curr Sports Med Rep, 11 (4), $209-216$.

Włodarek, D., Majkowski, M., Majkowska, L. (2012). Physical activity of elderly people living in district Koprzywnica. Rocz Panstw Zakl Hig, 63 (1), 111-117.

World Health Organization. (2010). Global recommendations on physical activity for health. Geneva. WHO Library Cataloguing-inPublication Data. Retrieved from: http://whqlibdoc.who.int/publications/2010/9789241599979_eng.pdf (10.03.2016).

Cite this apticle aS: Dębska, M., Mynarski, W., Rozpara, M., Puciato, D. (2017). Habitual Physical Activity in Adults Measured by Accelerometer in Compliance with Selected Health Recommendations. Central European Journal of Sport Sciences and Medicine, 18 (2), 99-105. DOI: 10.18276/cej.2017.2-10. 
